\title{
Desempenho e características de carcaça de cordeiros das raças Texel, Suffolk e cruza Texel x Suffolk ${ }^{1}$
}

\author{
Performance and characteristics of the carcass of lambs the breed Texel, \\ Suffolk and cross Texel $x$ Suffolk
}

\author{
Sérgio Carvalho ${ }^{2}$ André Vergueiro ${ }^{3}$ Roberto Kieling ${ }^{2}$ Regina Cánovas Teixeira ${ }^{2}$ \\ Josane Pivato $^{4}$ Renan Viero ${ }^{4}$ Alex Nunez da Cruz ${ }^{5}$
}

RESUMO

Este experimento objetivou comparar o desempenho $e$ as características de carcaça de 14 cordeiros, sendo quatro da raça Texel, cinco da raça Suffolk e cinco cruza Texel x Suffolk. Os cordeiros foram desmamados aos 64 dias de idade em média, $e$ terminados em regime de confinamento total, até o abate com idade média de 128 dias. Do nascimento ao desmame, as ovelhas (mães dos cordeiros) foram mantidas em pastagem nativa e receberam uma suplementação concentrada na proporção de $1 \%$ de peso vivo, tendo também os cordeiros acesso a uma suplementação concentrada na forma de creep-feeding na proporção de 1,5\% do peso vivo. $O$ alimento concentrado utilizado na suplementação das ovelhas e dos cordeiros continha $21 \%$ de proteína bruta (PB), $70 \%$ de nutrientes digestíveis totais (NDT), $2 \%$ de cálcio (Ca) e $0,4 \%$ de fósforo (P). Após o desmame, os cordeiros passaram a receber uma dieta composta por feno de Tifton-85 (Cynodon dactylon) + concentrado, na proporção 40:60 na Matéria Seca (MS), a qual continha 15,1\% de PB, 60,8\% de NDT, 1,4\% de Ca e $0,3 \%$ de $P$. O peso ao abate foi inferior $(P<0,05)$ nos cordeiros da raça Texel quando comparados aos cordeiros da raça Suffolk $e$ aos da cruza Texel x Suffolk. Os cordeiros cruza Texel x Suffolk tiveram um ganho de peso diário do nascimento ao abate superior $(P<0,05)$ quando comparados aos cordeiros da raça Texel. Os cordeiros cruza Texel x Suffolk também apresentaram um maior consumo de matéria seca $(P<0,01)$ quando comparados aos cordeiros das raças Suffolk e Texel, não havendo entretanto, diferenças entre as raças puras para esta variável. Não foram observadas diferenças estatísticas para as variáveis peso de carcaça quente, rendimento de carcaça quente, pernil, paleta e costilhar. Todavia, verificou-se uma menor porcentagem de pescoço $(P<0,05)$ nos cordeiros cruza Texel x Suffolk, quando comparados aos Suffolk.

Palavras-chave: ovino, confinamento, creep-feeding, carne, raça.

\section{ABSTRACT}

The objective of this work was to compare the performance and carcass characteristics of 14 lambs, being four of the Texel, five of the Suffolk and five cross Texel x Suffolk breeds. The lambs were weaned at 64 days of age in average, and finished in feedlot, until slaughtering with average age of 128 days. From birth to weaning, dams were maintained in native pasture and received a concentrated supplementation at a $1 \%$ ratio of live weight and lambs had access to a concentrated supplementation in the form of creep-feeding at a $1.5 \%$ ratio of the live weight. The concentrated food used in the supplementation of the sheep and the lambs contained $21 \%$ of crude protein (CP), $70 \%$ of total digestible nutrients (TDN), $2 \%$ of calcium (Ca) and $0.4 \%$ of phosphorus $(P)$. After weaning, lambs started to receive a composed diet of hay made of Tifton-85 (Cynodon dactylon) + concentrate, at a 40:60 ratio in the dry matter (DM), which contained $15.1 \%$ of CP, $60.8 \%$ of TDN, $1.4 \%$ of Ca and $0.3 \%$ of $P$. The slaughter weight was lower $(P<0.05)$ for the Texel purebred lambs when compared to Suffolk purebred lambs and Texel $x$ Suffolk crossbred lambs. The Texel x Suffolk crossbred lambs had higher birth to slaughtering weight daily gain $(P<0.05)$ when

\footnotetext{
${ }^{1}$ Parte do projeto de pesquisa "Desenvolvimento da Ovinocultura na Região do Vale do Rio do Sinos”. Kieling, bolsista de Iniciação Científica do Grupo de Estudos em Agronegócios do Centro Universitário Feevale

${ }^{2}$ Centro Universitário Feevale, RS 239, 2755, 93352-250, Novo Hamburgo, RS, Brasil. E-mail: sergiocarvalho@feevale.br. Autor para correspondência.

${ }^{3}$ Empresa BÜNGE Alimentos S.A., Novo Hamburgo, RS, Brasil. E-mail: andre.vergueiro@bunge.com

${ }^{4}$ Aluno de graduação do curso de Engenharia de Produção (Habilitação Agroindustrial) do Centro Universitário Feevale, Novo Hamburgo, RS, Brasil.

${ }^{5}$ Curso de Biologia do Centro Universitário Feevale, Novo Hamburgo, RS, Brasil.
} 
compared to Texel purebred lambs. The Texel $x$ Suffolk crossbred lambs presented a higher dry matter intake $(P<0.01)$ when compared to the Suffolk and Texel lambs, there were no differences between the pure breeds for this variable. Statistical differences were not observed for the variable hot carcass weight, hot carcass dressing, hindquarter, shoulder and ribs percentages. However, neck percentage was lower $(P<0.05)$ in the Texel x Suffolk crossbred was verified when compared with the Suffolk purebred lambs.

Key words: sheep, feedlot, creep-feeding, meat, breed.

\section{INTRODUÇÃO}

No Rio Grande do Sul, em face da crise sofrida pelo setor laneiro, a ovinocultura alicerçada na lã sofreu um golpe sem precedentes, o que levou a uma redução acentuada do efetivo do rebanho gaúcho. $\mathrm{Na}$ busca de alternativas que viessem a manter a sustentabilidade do setor, introduziram-se no Estado raças voltadas para a produção de carne.

De acordo com MACEDO et al. (1996), a procura pela carne ovina vem aumentando significativamente nos últimos anos, principalmente na região Sul e Sudeste do Brasil. Entretanto, as informações na área de produção de ovinos, embora recentemente tenham aumentado, ainda são escassas.

Conforme MÜLLER (1993), no Brasil o setor de produção de carne ovina e o mercado consumidor ainda são bastante reduzidos, sendo que a má apresentação do produto e o excesso de gordura na carcaça são fatores limitantes. Neste sentido, o uso de raças especializadas para produção de carne quando utilizadas puras ou através de cruzamentos são uma importante ferramenta na busca de carne ovina de qualidade.

Para CARDELLINO (1989) o cruzamento entre raças ovinas pode propiciar maior velocidade de crescimento, melhor conformação e melhor qualidade da carcaça e da carne. Portanto, a utilização de cruzamentos constitui uma forma de otimizar o crescimento e a qualidade do produto final e, conseqüentemente, a economicidade da cadeia produtiva.

Contudo, deve-se ter em mente que o fato de se realizar por si só o cruzamento com raças especializadas para produção de carne, não quer dizer necessariamente um produto melhor. Para que ocorra a expressão do potencial do cruzamento faz-se necessário um bom manejo sanitário e nutricional. Neste sentido, a nutrição adequada e a implantação de sistemas de manejo alimentar como o creep-feeding e o confinamento devem ser utilizados para obtenção de melhores desempenhos.
Segundo SILVA SOBRINHO et al. (1996) o creep-feeding é uma prática alimentar essencial nos sistemas intensivos de produção de ovinos, principalmente quando se deseja implantar o desmame precoce. Além disso, o uso de creep-feeding no período de lactação assume grande importância quando o desmame for seguido pela terminação dos cordeiros em confinamento, pois haverá um melhor desenvolvimento ruminal e uma maior facilidade no aprendizado para ingestão de alimentos sólidos no cocho por parte dos cordeiros.

O desmame precoce dos cordeiros seguido de confinamento, de acordo com BARBOSA (2004), aproveita o grande potencial das raças produtoras de carne proporcionando um rápido e eficiente crescimento. Além disso, para PEREIRA \& SANTOS (2001), este é um importante aspecto pois a intensificação na velocidade de crescimento muscular aliada a rápida terminação da carcaça parece ser a maneira mais factível e eficiente de se obter um produto de melhor qualidade e de competitividade no mercado consumidor de carne ovina.

O objetivo deste trabalho foi de avaliar o desempenho e as características da carcaça de cordeiros das raças Texel, Suffolk e cruza Texel x Suffolk, suplementados durante o período de amamentação via creep-feeding e posteriormente terminados em confinamento após o desmame.

\section{MATERIAL E MÉTODOS}

O experimento foi conduzido, em sua fase de campo, nas instalações de ovinocultura em uma propriedade rural situada no município de Estância Velha, RS, e em sua fase laboratorial no Centro Universitário Feevale em Novo Hamburgo, RS. O trabalho foi realizado de agosto de 2003 a janeiro de 2004.

Foram utilizados 14 cordeiros machos não castrados, sendo quatro da raça Texel, cinco da raça Suffolk e cinco cruza Texel x Suffolk. A partir do terço final de gestação todas as ovelhas permaneceram durante o dia em uma área de pastagem nativa e a noite eram suplementadas em um aprisco, onde recebiam uma suplementação concentrada na proporção de $1 \%$ do peso vivo. Vinte e quatro horas após o parto, os cordeiros e suas respectivas mães, foram pesados, identificados e colocados em uma área experimental com pastagem nativa, onde permaneciam durante o dia. À noite, os animais (ovelhas + cordeiros) eram encerrados em um aprisco, em baia coletiva, com piso ripado, onde as ovelhas recebiam uma suplementação concentrada na proporção de $1 \%$ de peso vivo e os 
cordeiros tinham acesso a uma suplementação concentrada na forma de creep-feeding na proporção de $1,5 \%$ do peso vivo. A suplementação concentrada das ovelhas ocorreu do terço final de gestação (últimos 50 dias) até o desmame e dos cordeiros a partir de 7 dias de idade até o desmame. Quando os cordeiros atingiram em média 64 dias de idade, os mesmos foram desmamados e em seguida confinados em baias individuais, com piso ripado, onde permaneceram até o abate.

Utilizou-se alimento concentrado comercial na suplementação das ovelhas e dos cordeiros, sendo que o mesmo foi fornecido pela empresa BÜNGE Alimentos S.A., e continha $21 \%$ de proteína bruta (PB), $70 \%$ de nutrientes digestíveis totais (NDT), 2\% de cálcio (Ca) e 0,4\% de fósforo (P). Após o desmame, os cordeiros passaram a receber uma dieta composta por Feno de Tifton-85 (Cynodon dactylon) + concentrado, na proporção 40:60 na Matéria Seca (MS), contendo 15,1\% de PB, 60,8\% de NDT, 1,4\% de $\mathrm{Ca}$ e $0,3 \%$ de $\mathrm{P}$. O alimento concentrado utilizado foi o mesmo fornecido na suplementação durante o período de amamentação. Os animais tinham acesso à água e sal comum à vontade em comedouros específicos para suplementação mineral.

A quantidade total de alimento (suplementação e confinamento) oferecida diariamente foi dividida em dois horários, sendo os animais alimentados duas vezes ao dia, as 8 e 18 horas. No confinamento, a quantidade oferecida foi ajustada em função da sobra observada diariamente, sendo que esta foi controlada para que fosse $10 \%$ da quantidade oferecida no dia anterior, de modo a garantir o consumo voluntário dos animais. Periodicamente foram coletadas amostras dos alimentos oferecidos e das sobras, sendo que as análises laboratoriais de MS foram realizadas na Central Analítica do Centro Universitário Feevale, em Novo Hamburgo, RS. A conversão alimentar foi calculada apenas no período após o desmame, sendo considerando o consumo de matéria seca de Feno de Tifton-85 + concentrado do desmame até o abate (período de confinamento).

As pesagens dos cordeiros foram realizadas 24 horas após o nascimento, ao desmame e imediatamente antes do abate. Além dessas, foram realizadas pesagens intermediárias a cada 14 dias. As pesagens ao desmame e antes do abate foram realizadas pela manhã, posterior a um jejum de sólidos de 14 horas.

Após o abate, a carcaça de cada animal foi pesada e em seguida separada ao meio, de forma simétrica, longitudinalmente, deixando a cola no lado esquerdo. A metade direita da carcaça foi pesada e separada regionalmente nos seguintes cortes comerciais: pescoço, paleta, costilhar e pernil (ou quarto). Após a separação regional, os diferentes cortes comerciais foram pesados e sua porcentagem calculada em relação ao peso da carcaça. A separação regional foi realizada segundo OSÓRIO et al. (1998). As carcaças não foram resfriadas devido à ausência de câmara frigorífica no local de abate. O rendimento de carcaça quente foi calculado dividindo-se o peso de carcaça quente pelo peso vivo ao abate.

Os dados coletados foram submetidos à análise de variância pelo GLM e ao teste t (Student PDIFF) ao nível de 5\% de significância, utilizando-se o pacote estatístico SAS (1993).

\section{RESULTADOS E DISCUSSÃO}

Na tabela 1, são apresentados os valores médios para peso ao nascimento, peso ao desmame, peso final, idade ao desmame e idade ao abate, de acordo com a raça dos cordeiros. Os cordeiros da raça Texel apresentaram peso médio ao nascimento inferior $(\mathrm{P}<0,05)$ quando comparados aos cordeiros da raça Suffolk e cruza Texel x Suffolk. Neste sentido, o resultado encontrado concorda com a afirmativa de

Tabela 1 - Peso vivo ao nascimento (PV-N), peso vivo ao desmame (PV-D), peso vivo ao abate (PV-A), idade ao desmame (ID) e idade ao abate (IA) dos cordeiros, de acordo com os diferentes genótipos.

\begin{tabular}{|c|c|c|c|c|c|c|}
\hline \multirow{2}{*}{ Variáveis } & \multicolumn{3}{|c|}{ Genótipos } & \multirow{2}{*}{ Média } & \multirow{2}{*}{$\operatorname{Pr}>F$} & \multirow{2}{*}{ CV (\%) } \\
\hline & Texel & Suffolk & Texel x Suffolk & & & \\
\hline $\mathrm{PV}-\mathrm{N}$ & $3,33^{b} \pm 0,21$ & $4,82^{\mathrm{a}} \pm 1,24$ & $5,20^{a} \pm 0,28$ & 4,55 & 0,0362 & 17,31 \\
\hline PV-D & $21,80^{\mathrm{b}} \pm 3,31$ & $24,42^{\mathrm{b}} \pm 3,89$ & $31,90^{\mathrm{a}} \pm 3,00$ & 26,43 & 0,0113 & 13,16 \\
\hline PV-A & $37,73^{\mathrm{b}} \pm 2,37$ & $43,92^{\mathrm{a}} \pm 4,67$ & $48,25^{\mathrm{a}} \pm 1,58$ & 43,81 & 0,0090 & 7,41 \\
\hline ID & $63,33 \pm 5,03$ & $60,25 \pm 5,85$ & $69,25 \pm 5,18$ & 64,36 & 0,1168 & 8,41 \\
\hline IA & $126,0 \pm 3,60$ & $128,5 \pm 3,69$ & $128,5 \pm 5,06$ & 127,8 & 0,6963 & 3,32 \\
\hline
\end{tabular}

Médias seguidas por letras diferentes, na mesma linha, diferem $(\mathrm{P}<0,05)$ pelo teste $\mathrm{t}$.

Ciência Rural, v.35 n. 5, set-out, 2005. 
PIRES et al. (2000), de que o peso ao nascimento está diretamente relacionado a fatores de ordem genética, o que foi observado no presente estudo. Segundo estes mesmos autores, quando as ovelhas são submetidas às mesmas condições alimentares durante o período de gestação, os cordeiros Suffolk e suas cruzas nascem mais pesados do que os da raça Texel.

O peso vivo ao abate dos cordeiros cruza Texel x Suffolk foi 27,9\% superior $(\mathrm{P}<0,05)$ quando comparado aos da raça Texel. Este resultado obtido pode ser explicado pela afirmativa de PÉREZ \& PILAR (2002), de que o vigor híbrido obtido pelo cruzamento proporcionará nos mestiços (F1), aumento da produtividade nas fases de cria e terminação devido a maior velocidade de crescimento, comparado com os puros da raça materna.

As médias para ganho de peso diário do nascimento ao desmame, ganho de peso diário do desmame ao abate, ganho de peso diário do nascimento ao abate, consumo de matéria seca e conversão alimentar, de acordo com o genótipo dos cordeiros, são apresentadas na tabela 2 . O ganho de peso diário do nascimento ao desmame (GPD-D) dos cordeiros da raça Texel foi inferior $(\mathrm{P}<0,05)$ aos dos cordeiros da raça Suffolk e da cruza Texel x Suffolk. Não houve diferença significativa $(\mathrm{P}>0,05)$ entre os genótipos com relação ao ganho de peso médio diário do desmame ao abate (GPD-A). O menor ganho de peso diário verificado nos cordeiros da raça Texel no período de amamentação foi determinante para que houvesse um menor ganho de peso diário do nascimento ao abate (GPD-TOTAL) destes animais quando comparado com os cordeiros cruza Texel x Suffolk. Contudo, o ganho de peso diário total não diferiu $(\mathrm{P}>0,05)$ entre cordeiros Texel e Suffolk, e entre cordeiros Suffolk e cruza Texel x Suffolk.

O ganho de peso diário médio observado nos diferentes genótipos no período de amamentação (GPD-D), de 338g, está de acordo com PIRES et al. (2000), que observaram um ganho de peso de 336g dia-1 em cordeiros filhos de carneiros Texel com ovelhas cruza, confinados do nascimento ao desmame com 45 dias de idade. Está próximo também ao observado por CARVALHO et al. (1999), que verificaram em cordeiros machos não castrados cruza Texel x Ideal, confinados com suas respectivas mães do nascimento ao desmame aos 50 dias de idade, um ganho de peso médio diário de 316g.

Ao comparar-se o período de amamentação com o período de confinamento pós-desmame, podese observar uma redução de 19,5\% (338 para 272g) no ganho de peso médio diário dos cordeiros dos diferentes genótipos. Esta diminuição no ganho de peso pode ser explicada pela ausência do leite das ovelhas na dieta dos cordeiros a partir do desmame. Contudo, outros autores têm verificado reduções mais acentuadas no ganho de peso dos cordeiros em função do desmame. Neste sentido CARVALHO et al. (1999), verificaram uma redução no ganho de peso de cordeiros após o desmame de 53,1\%, e PIRES et al. (2000) de 47,6\%. Os autores atribuíram esta redução à ausência de leite materno e ao baixo consumo de alimentos pelos cordeiros, principalmente nos dias logo após o desmame. Provavelmente, no presente experimento, a suplementação concentrada oferecida para os cordeiros no creep-feeding foi importante para adaptação dos cordeiros à dieta sólida, o que fez com que a queda de peso após o desmame não ocorresse de forma tão acentuada.

Com relação ao consumo de matéria seca, observa-se na tabela 2 que os cordeiros cruza Texel x Suffolk apresentaram um consumo superior $(\mathrm{P}<0,01)$ quando comparados aos cordeiros das raças Suffolk e Texel, não havendo entretanto, diferenças entre as raças puras para esta variável. O maior consumo de MS verificado nos cordeiros cruza Texel x Suffolk pode ser atribuído em parte ao maior peso vivo destes animais (tabela 1). Contudo, ao observar-se a conversão alimentar, observa-se que não houve diferença estatisticamente significativa $(\mathrm{P}>0,05)$ entre os tratamentos. $\mathrm{O}$ valor médio observado nos diferentes grupos genéticos de 4,03:1 para conversão alimentar pode ser considerado satisfatório demonstrando uma grande eficiência dos cordeiros na utilização do alimento. Valores superiores para conversão alimentar foram obtidos por PILAR et al. (1994), que trabalhando com cordeiros de cinco genótipos verificaram um valor médio de 6,18:1 e por PIRES et al. (1999), que avaliando o desempenho de cordeiros de três grupos genéticos, obtiveram um valor médio de 7,98:1. Contudo, deve-se salientar que estes autores trabalharam com cordeiros com idade superior aos do presente estudo, o que explica a diferença observada. Sabe-se que a conversão alimentar é aumentada à medida que aumenta a idade e o peso vivo, sendo isso proporcionado pela elevação do consumo de matéria seca (g/animal/dia) em relação ao ganho de peso (g/ animal/dia) dos animais. Quando compara-se o valor médio obtido no atual experimento para conversão alimentar com cordeiros de idade semelhante, encontrase concordância com PIRES et al. (2000), os quais verificaram uma conversão alimentar de 4,24:1, em cordeiros filhos de carneiro Texel com ovelhas cruza, confinados do desmame ao abate aos 118 dias de idade. Estes resultados também estão próximos ao resultado obtido por CARVALHO et al. (1999), os quais 
Tabela 2 - Ganho de peso diário do nascimento ao desmame (GPD-D), ganho de peso diário do desmame ao abate (GPD-A), ganho de peso diário do nascimento ao abate (GPD-TOTAL), consumo de matéria seca (CMS) e conversão alimentar (CA) dos cordeiros, de acordo com os diferentes genótipos.

\begin{tabular}{|c|c|c|c|c|c|c|}
\hline \multirow{2}{*}{ Variáveis } & \multicolumn{3}{|c|}{ Genótipos } & \multirow{2}{*}{ Média } & \multirow{2}{*}{$\operatorname{Pr}>\mathrm{F}$} & \multirow{2}{*}{ CV (\%) } \\
\hline & Texel & Suffolk & Texel x Suffolk & & & \\
\hline GPD-D & $0,291^{\mathrm{b}} \pm 0,03$ & $0,325^{\mathrm{a}} \pm 0,03$ & $0,387^{\mathrm{a}} \pm 0,05$ & 0,338 & 0,0345 & 11,87 \\
\hline GPD-A & $0,255 \pm 0,01$ & $0,281 \pm 0,04$ & $0,276 \pm 0,03$ & 0,272 & 0,6599 & 13,68 \\
\hline GPD-TOTAL & $0,274^{\mathrm{b}} \pm 0,02$ & $0,304^{\mathrm{ab}} \pm 0,02$ & $0,335^{\mathrm{a}} \pm 0,01$ & 0,307 & 0,0179 & 7,08 \\
\hline CMS & $0,981^{\mathrm{b}} \pm 0,01$ & $0,988^{\mathrm{b}} \pm 0,02$ & $1,254^{\mathrm{a}} \pm 0,01$ & 1,083 & 0,0001 & 1,57 \\
\hline CA & $3,85 \pm 0,25$ & $3,59 \pm 0,59$ & $4,60 \pm 0,61$ & 4,03 & 0,0706 & 13,35 \\
\hline
\end{tabular}

Médias seguidas por letras diferentes, na mesma linha, diferem $(\mathrm{P}<0,05)$ pelo teste $\mathrm{t}$.

verificaram em cordeiros machos não castrados, oriundos do acasalamento de carneiro da raça Texel com ovelhas cruza, e abatidos com 100 dias de idade, um valor médio de 3,76:1.

Na tabela 3, são apresentados os valores médios para peso de carcaça quente, rendimento de carcaça quente e para as porcentagens de pernil, paleta, costilhar e pescoço, de acordo com os genótipos dos cordeiros. Os cordeiros cruza Texel x Suffolk apresentaram uma menor porcentagem de pescoço $(\mathrm{P}<0,05)$ quando comparados aos Suffolk, sendo que não houve diferença entre os cordeiros das raças Texel e Suffolk. Para as demais variáveis analisadas, não foram encontradas diferenças significativas entre os tratamentos.

O valor médio obtido de 21,54kg para peso de carcaça quente em cordeiros abatidos com uma idade média de 127,8 dias, pode ser considerado plenamente satisfatório, o que demonstra o bom resultado obtido neste experimento. Isso fica evidente ao comparar-se o valor médio encontrado no presente estudo com o obtido por CUNHA et al. (2004), os quais verificaram em cordeiros Suffolk desmamados aos 60 dias de idade e confinados até o abate com 132 dias, um peso de carcaça quente de $16,0 \mathrm{~kg}$. Resultado inferior ao do presente estudo foi também obtido por SANTOS et al. (2004), os quais comparando cordeiros machos de quatro genótipos suplementados em creep-feeding do nascimento até o desmame aos 60 dias de idade, e confinados do desmame ao abate com idade média de 120 dias, obtiveram um valor médio de 13,6kg para peso de carcaça quente.

Quanto ao rendimento de carcaça quente, deve-se destacar o bom resultado encontrado no presente estudo, o que é importante do ponto de vista econômico e produtivo, pois é através do rendimento de carcaça que uma menor ou maior porção de material comestível torna-se disponível para comercialização e consumo após o abate dos animais. Além disso, de acordo com SOUZA (1993) e PÉREZ (1995), o rendimento é que determina o maior ou menor custo da carne para o consumidor, motivo relevante para despertar o interesse para esse parâmetro, sendo um incentivo para os criadores que investem nesta atividade.

Tabela 3 - Valores médios para peso de carcaça quente (PCQ), rendimento de carcaça quente (RCQ) e para as porcentagens de pernil (PER), paleta (PAL), costilhar (COST) e pescoço (PESC) dos cordeiros, de acordo com os diferentes genótipos.

\begin{tabular}{|c|c|c|c|c|c|c|}
\hline \multirow{2}{*}{ Variáveis } & \multicolumn{3}{|c|}{ Genótipos } & \multirow{2}{*}{ Média } & \multirow{2}{*}{$\operatorname{Pr}>F$} & \multirow{2}{*}{ CV (\%) } \\
\hline & Texel & Suffolk & Texel x Suffolk & & & \\
\hline PCQ (kg) & $18,25 \pm 1,15$ & $21,45 \pm 3,75$ & $24,11 \pm 2,14$ & 21,54 & 0,0619 & 12,57 \\
\hline RCQ (\%) & $48,38 \pm 0,81$ & $48,56 \pm 3,51$ & $49,91 \pm 2,95$ & 49,00 & 0,7287 & 5,79 \\
\hline PER (\%) & $32,74 \pm 0,50$ & $33,00 \pm 0,59$ & $33,55 \pm 1,49$ & 33,13 & 0,5788 & 3,07 \\
\hline PAL (\%) & $20,52 \pm 1,47$ & $19,37 \pm 0,28$ & $20,25 \pm 0,58$ & 20,01 & 0,2152 & 4,19 \\
\hline COST (\%) & $39,29 \pm 0,86$ & $39,45 \pm 0,87$ & $39,49 \pm 1,95$ & 39,42 & 0,9792 & 3,49 \\
\hline PESC (\%) & $7,45^{\mathrm{ab}} \pm 0,72$ & $8,17^{\mathrm{a}} \pm 1,04$ & $6,60^{\mathrm{b}} \pm 015$ & 7,40 & 0,0481 & 9,97 \\
\hline
\end{tabular}

Médias seguidas por letras diferentes, na mesma linha, diferem $(\mathrm{P}<0,05)$ pelo teste $\mathrm{t}$.

Ciência Rural, v.35 n. 5, set-out, 2005. 
O valor médio obtido dos diferentes grupos genéticos de 49,0\% para o rendimento de carcaça quente foi superior ao encontrado por CUNHA et al. (2004), os quais avaliaram as características de carcaça de cordeiros de algumas raças de corte, e verificaram em cordeiros da raça Suffolk, desmamados aos 60 dias e confinados até o abate aos 132 dias de idade, um rendimento de carcaça quente de $46,1 \%$.

Verificou-se uma menor porcentagem de pescoço nos cordeiros cruza Texel x Suffolk. Contudo, as percentagens de pernil, paleta e costilhar não diferiram entre os genótipos avaliados. Os valores médios encontrados para as porcentagens de pernil, paleta e pescoço, estão de acordo com PEREIRA et al. (2001), os quais observaram em cordeiros da raça Corriedale, machos não castrados e abatidos aos 123 dias de idade, valores médios de $35,7 \%, 21,2 \%$ e $8,2 \%$, respectivamente. Contudo para a porcentagem de costilhar, esses autores encontraram um valor médio $4,5 \%$ inferior ao do presente estudo.

\section{CONCLUSÕES}

Cordeiros da raça Suffolk e cruza Texel x Suffolk apresentam ganho de peso superior em relação a cordeiros da raça Texel quando submetidos a sistema de creep-feeding do nascimento ao desmame. O ganho de peso do nascimento ao abate é superior em cordeiros cruza Texel x Suffolk quando comparados com cordeiros Texel.

Cordeiros cruza Texel x Suffolk, quando submetidos a regime de confinamento, apresentam consumo de matéria seca superior em relação a cordeiros das raças Texel e Suffolk e uma menor porcentagem de pescoço do que cordeiros da raça Suffolk.

\section{REFERÊNCIAS}

BARBOSA, J.A. Sistema de produção de cordeiros Capturado em 26 jun. 2004. Online. Disponível na Internet: http://www.vaccinar.com.br/artigos9.htm.

CARDELlino, R.A. Produccion de carne ovina basada en cruzamientos. SELECCIÓN DE TEMAS AGROPECUÁRIOS. Montevideo: Hemisferio Sur, 1989. p.2331.

CARVALHO, S. et al. Desempenho de cordeiros machos inteiros, machos castrados e fêmeas, alimentados em confinamento. Ciência Rural, Santa Maria, v.29, n.1, p.129-133, 1999.

CUNHA, E.A., et al. Características de carcaça de cordeiros de raças de corte criados intensivamente. Capturado em 05 de jul. 2004. Online. Disponível na Internet: www.ovinosbrasil.com/trab_tec/pg_trab_tecs_014.htm.
MACEDO, F.A.F. et al. Desenvolvimento de cordeiros puros e cruzados, terminados em pastagem ou confinamento. In: REUNIÃO DA SOCIEDADE BRASILEIRA DE ZOOTECNIA, 34., 1997, Fortaleza, CE. Anais... Fortaleza: Sociedade Brasileira de Zootecnia, 1996. p.154-156.

MÜLLER, L. Qualidade da carne - tipificação de carcaças bovinas e ovinas. In: SIMPÓSIO DA REUNIÃO ANUAL DA SOCIEDADE BRASILEIRA DE ZOOTECNIA, 30., 1993, Rio de Janeiro. Anais... Rio de Janeiro: Sociedade Brasileira de Zootecnia, 1993. p.53-69.

OSÓRIO, J.C.S. et al. Métodos para avaliação da produção de carne ovina, in vivo, na carcaça e na carne. Pelotas: UFPEL, 1998. 107p.

PEREIRA, P.S. et al. Efeito da castração sobre a composição regional e tecidual em cordeiros Corriedale. Zootecnia Tropical, 19, Supl.1, p.297-305, 2001.

PEREIRA, J,R,A.; SANTOS, I.C. Sistema intensivo de produção de ovinos. In: UEPG, 2001. p. $\overline{7-20}$.

PEREZ, J.R.O. Alguns aspectos relacionados com a qualidade da carcaça e da carne ovina. In: SIMPÓSIO PAULISTA DE OVINOCULTURA, 4., 1995, Campinas. Anais... Campinas: ASPACO-CATI-FMVZ/UNESPSENAR, 1995. p.125-139.

PEREZ, J.R.O.; PILAR, R.C. Raças ovinas e cruzamentos de interesse zootécnico. In: Ovinocultura: alguns conceitos. Lavras: Universidade Federal de Lavras, Departamento de Zootecnia, Grupo de Apoio a Ovinocultura, 2002. p.1-21.

PILAR, R.C. et al. Desempenho em confinamento e components do peso vivo de diferentes genótipos de ovinos abatidos aos doze meses de idade. Ciência Rural, Santa Maria, v.24, n.3, p.607-612, 1994.

PIRES, C.C. et al. Desempenho e características da carcaça de cordeiros de três grupos genéticos abatidos ao mesmo estágio de maturidade. Ciência Rural, Santa Maria, v.29, n.1, p.155158, 1999

PIRES, C.C. et al. Cria e terminação de cordeiros confinados. Ciência Rural, Santa Maria, v.30, n.5, p.875-880, 2000.

SANTOS, L.E. et al. Desempenho e características da carcaça de cordeiros Santa Inês e cruzados com raças especializadas para corte. Capturado em 26 jun. 2004. Online. Disponível na Internet: http://www.ovinosbrasil.com/ trab_tec/pg_trab_tecs_017.htm.

STATISTICAL ANALYSES SYSTEM - SAS. User's guide. , Version 6.8. Cary: North Carolina, 1993. 956p.

SILVA SOBRINHO, A.G. et al. Nutrição de ovinos. Jaboticabal: FUNEP, 1996. 258p.

SOUZA, O.C.R. Rendimento de carcaça, composição regional e física da paleta e quarto em cordeiros Romney Marsh abatidos aos 90 e 180 dias de idade. 1993. 102f. Dissertação (Mestrado em Zootecnia) - Curso de Pós-graduação em Zootecnia, Universidade Federal de Pelotas. 